Journal of Research in Interprofessional

Practice and

Education

Vol. 6.2

2016

\title{
Moving the Interprofessional Education Research Agenda Beyond the Limits of Evaluating Student Satisfaction
}

\author{
Sharon Lawn \\ Flinders University of South Australia
}

\begin{abstract}
Background: Much of the research on the impact of interprofessional education (IPE) interventions is hampered by a lack of focus on whether they were successfully translated to effective interprofessional practice (IPP).

Methods and Findings: This article reports the outcomes of a think tank of Australian IPE researchers who articulated these gaps and brainstormed types of research and research questions needed to help address these gaps. A social constructivist theoretical approach was proposed, including more ethnographic and longitudinal investigation.

Conclusions: A greater focus on theory is needed to understand the underlying processes involved in IPE, IPP, and the transition between them. This will involve researchers employing more qualitative and mixed-method approaches in addition to the quantitative methods that appear to dominate this field, currently.

Keywords: Interprofessional education; Qualitative research; Transformative education; Theory
\end{abstract}

\section{Introduction}

This article provides a discussion of some of the gaps that exist in current interprofessional education (IPE) research and offers a range of ideas for how to address these gaps. Its aim is, therefore, to stimulate further thinking and provide a useful set of building block ideas that could form the basis of a comprehensive research agenda for progressing this work in Australia and internationally. The article arose in the context of a presentation at the inaugural Interprofessional Health Education and Practice International Conference, held in Melbourne, Australia, in October 2015. It was informed by work undertaken during 2014 at Flinders University by the author and a dedicated IPE Project Working Group at their university, tasked with being a "think tank" for how IPE could be embedded more collaboratively across its Faculty

Journal of Research in Interprofessional Practice and Education (JRIPE)

Vol. 6.2

(C) 2016

Corresponding author: Sharon Lawn. Email:

Sharon.lawn

@flinders.edu.au of Medicine, Nursing and Health Sciences, with reach to social science faculty disciplines such as psychology and social work.

The Project Working Group comprised 12 academics from across all of these disciplines, with an active interest and engagement in IPE. All members were active in university teaching and research and had been for at least five years; most had more than ten years' experience working in this space. The working group met approximately monthly for a period of nine months, with a half-day workshop held near the end of that period and further electronic feedback to finalize the discussions, focused 
2

IPE Research Agenda

Lawn
Journal of Research in Interprofessional Practice and Education

Vol. 6.2

2016 specifically on brainstorming what a research agenda might entail. This formative work had been undertaken to prepare for the development of a faculty-wide strategic focus on embedding IPE more systematically across the medical, nursing, and allied health curricula.

Our IPE efforts were informed by the Centre for the Advancement of Interprofessional Education (CAIPE) [1] definition of IPE as being, "When two or more professions learn with, from and about each other in order to improve collaboration and the quality of care." Our concern was that the existing suite of IPE research did not appear to have moved us very far in understanding the nuances of "with, from and about" to a level of depth that could translate readily to interprofessional practice (IPP) and distinguish it from generally understood multidisciplinary care. IPP, as understood here, is the desired outcome of IPE and involves the interdependent attributes required by professionals for effective collaboration, such as effective communication and teamwork, including a shared vision for client-centred care, mutual support, and respect for the contributions of each stakeholder [2].

\section{Identifying a core research gap: Measuring the meaningful translation of IPE to practice}

The national Office for Learning and Teaching-funded IPE Curriculum Renewal Consortium, which is a collaboration between Australia's current leading IPE researchers, has argued that much of the existing evidence for IPE is derived from research that is value-based rather than outcome-based and is of limited duration, depth, and rigour [3]. It has focused primarily on study participants' satisfaction with the learning activity [4]. For example, a recent national audit of IPE identified, "the lack of a substantial evaluation and research base to provide comment on the use, implications and outcomes of different methods, configurations, sequencing, and contexts for IPE learning activities" [3, p. 48]. Where studies are more outcomebased, their primary focus has been on "did it work?" [4], and fail to fully understand "why" and "how" the interventions worked, and whether their perceived positive outcomes were maintained over time. Such questions can only be answered with carefully constructed and conducted longitudinal research that enables the researcher to observe and understand how organizational and individual behaviours are "played out" as part of the implementation and sustainability of change over time.

These problems have arisen because previous studies have been limited by small sample sizes and an inability to show "cause and effect" relationships between stated intentions and outcomes attributed to the educational intervention. Why different approaches might be more or less effective in preparing students for interprofessional practice (IPP) remains elusive [5]. Pollard, Miers, and Rickaby go further in arguing that there has been, "no clear evidence that pre-qualifying IPL [interprofessional learning] improves service delivery" [6, p. 355]. To help address this, their own study comparing the perceptions of health professions exposed to IPE with those who had not had such exposure found that the IPE group, "showed a great awareness of the value of reflection on practice and a more complex understanding of team- 
3

IPE Research Agenda

Lawn
Journal of Research in Interprofessional Practice and Education

Vol. 6.2

2016 working, including their own part within it, attributes which can help practitioners function effectively in an IP [interprofessional] environment" [6, p. 359].

Existing IPE research has been heavily influenced by and focused on selfreported pre-post evaluation of specific one-off or short-term IPE activities, often located at single sites with small, purposive samples [7]. Scales to measure these processes and events have proliferated and become a dominant feature of the IPE research discourse. Such scales have been used to measure dedicated domains such as: readiness, for example, the Readiness of Interprofessional Learning (RIPLs) scale by Parsell and Bligh [8, see also 9,10]; self-efficacy, for example, the Self-Efficacy for Interprofessional Learning (SEIEL) scale by Mann, McFetridge-Durdle, Breau, Clovis, Martin-Misener, Matheson, Beanlands, and Sarria [11]; facilitation, for example, the Interprofessional Facilitation Scale (IPFS) by Sargeant, Hill, and Breau [12]; and satisfaction, for example, the Interprofessional Education Perception Scale (IEPS) by Solomon and Salfi [13].

Kirkpatrick and Kirkpatrick's evaluation typology [14] and, more recently, Barr, Koppel, Reeves, Hammick, and Freeth's six-level learner outcome hierarchy that is drawn from this typology [15] has underpinned much of this evaluation work. Reeves, Boet, Zierler, and Kitto [7], in their systematic review report of IPE studies found that the CAIPE definitions were pervasive across most studies, and that the Kirkpatrick typology was fundamental to the classification of outcomes for most studies. They also noted clear concerns with educational-methodological dissonance, and heterogeneity across the studies.

Malt's [16] Cochrane systematic review of 22 studies investigating the effectiveness of IPE to separate profession-specific education intervention and no intervention found some evidence for improved patient outcomes and professional practice where IPE had occurred, though he suggests caution due to the heterogeneity of the studies. Reeves, Perrier, Goldman, Freeth, and Zwarenstein [17] made similar conclusions in their systematic review of 15 studies. They recommended more research in three main areas: comparative studies between IPE interventions and separate profession-specific interventions; trials and before-after studies that also included qualitative methods examining processes in more detail; and cost-benefit analyses.

Few studies use theory to understand the processes underpinning IPE. Olson and Bialocerkowski have argued that, "IPE research is currently caught in an epistemological struggle, between assumptions underpinning biomedical and health science research, and those underpinning education studies" [18, p. 236]. They have argued that the research has been dominated by a positivist paradigm focused on measurement, rather than more qualitative approaches that could concentrate efforts on more reflection on and understanding of underlying processes to help explore and explain the longer-term outcomes of IPE. More recently, there are some signs that research with stronger theoretical underpinnings is being considered. One Australian example is the use of complexity theory in the development and evaluation of a student-directed learning activity, chosen because it "de-emphasise[s] the individual and focus[es] on the dynamic social nature of learning" $[19$, p. 200]. 
4

IPE Research

Agenda

Lawn
Journal of Research in Interprofessional Practice and Education

Vol. 6.2

2016
Essentially, the existing IPE literature confirms that we know little about what theoretical processes determine the construction of meaning of IPE and its translation to practice; that is, the underlying processes that occur between teachers, learners, and the learning environment that move students from value-based satisfaction with IPE curricula to embedding it into their later collaborative practice [20]. There are significant limitations to how these processes are currently measured.

\section{Addressing this gap}

When we undertake IPE research, our primary interest is in the type of constructions students make about themselves and others and their collaborative practice; for example, how IPE has helped shape their learning approaches, their views and conceptions of the expertise of other disciplines, and how it has helped in shaping and reshaping their own values regarding patient care. This is because we want to investigate whether the IPE activities we teach have created a change in the quality of students' constructions. This suggests that a social-constructivist approach might be useful.

Social-constructivist/cognitivist views on human learning state that it needs to be an active process that is meaningful to the learner. If the learner fails to make sense of what has to be learned, or in other words if he/she is not able to couple it to his/her pre-existing knowledge (his/her semantic networks), the learning fails. This coupling is more efficient if it is an active process in which the learner actively establishes as many connections between the new knowledge and his/her semantic networks as possible [21,22]. Collaborative learning, triggering the learner to approach these connections from a wide variety of angles, is therefore even more efficient and this is where IPE can play a pivotal role in the learning process. But this can only work if the learner sees these effects on his/her own learning, i.e., when it aligns with his/her own constructions, values, and beliefs about learning. Hence, a strong focus on reflection is indicated. Mezirow's [23] transformative learning theory may offer a further conceptual framework that can inform this reflection by encouraging deep learning from everyday experiences in which the learners make meaning of their lives based on the context in which learning occurs and in which they formulate different frames of reference that challenge their previously held assumptions. Patients and their families are key players who are integrally involved in shaping student learning, particularly as part of the many direct experiences that students are exposed to during practice placements. Transformative learning is also apparent within the patientcentred and family-centred collaborative practice that is central to health professionals' IPP, through ongoing reflective practice.

By addressing the above identified research gap from a cognitivist/social constructivist angle, we are better placed to develop IPE curricula in which the complexity of IPE aligns with the ability of students to construct meaning at each stage of their journey through the curriculum. This is because, if they do not see the meaning of the IPE and how it leads to their own professional development, they cannot construct meaningful knowledge and understanding of it and it is too complex. This core focus on understanding how students construct meaning from IPE learning 
5

IPE Research Agenda

Lawn
Journal of Research in Interprofessional Practice and Education activities could be complemented with a range of smaller research topics, which could link with each other or could be independent, separate studies.

\section{Potential research topics}

The following list of potential research topics, derived from the IPE Project Working Group is offered as a way forward to help address the current gaps in how IPE translation to practice is understood and measured. These topics encompass a range of research methodologies and designs, including qualitative, quantitative, and mixedmethods studies. They also offer research options that would suit a full range of research experience from novice to experienced researchers. The order in which they appear here does not represent greater or lesser priority.

1. A social network analysis (SNA) $[24,25]$ to provide a more dynamic approach to the evaluation of the student learning process and also IPP. Current evaluation tends to be linear, focusing on inputs and outputs, and is arguably confined to health professionals looking only at themselves and the immediate context in which they deliver healthcare. SNA uses the concepts of empower, collaborate, involve, consult, and inform as the means to assess the impact of networks, and these are assessed through addressing network density, reciprocity, transitivity, and centrality $[24,25]$. An SNA would be useful for broadening the research lens by incorporating methods and underpinning methodology from other disciplines, such as anthropology and implementation science [see also 26,27]. This would then enable deeper investigation of the following:

- Analyzing the characteristics and structure of relationships between students and between health professionals;

- Measuring the structure of student placement;

- Understanding how students learn what they learn, whether this differs for different students, and why;

- Investigating official and unofficial ways of learning for individuals and groups;

- Mapping how IPP groups develop over time, and

- Understanding how students develop IPP capabilities over time. We know that it takes some time for the collaborative learning process to really start working well. Hommes' [22] work on how time influences the timing of collaborative learning is useful here.

2. An ethnographic study of IPE learning and IPP environments (for example, observation of the classroom, simulation centre, placement environment, or case conferences). Reeves Kuper, and Hodges state, "The central aim of ethnography is to provide rich, holistic insights into people's views and actions ... to 'get inside' the 
6

IPE Research

Agenda

Lawn
Journal of Research in Interprofessional Practice and Education way each group of people sees the world" [28, p. 512]. Observation of the planned "team" meetings is useful because, as Arber argues, "The alignment of different agendas proceeds through talk-inaction in the team meetings, and this is a complex process involving disciplinary knowledge but it is also a social process" $[29$, p. 1323]. Both structured and unstructured ethnographic observation methods could be used, as recommended for observation studies [30]. Structured observations could be set within the methods used by Hendry and Seidl [31]. Their overarching framework involves looking at the meeting processes of initiation (for example, how authority is conferred within meeting structures), conduct (for example, how the meeting conversation develops around particular items), and termination (for example, how items within meetings are either resolved or referred to other meetings). During meetings, the researcher could then note examples of interactions-for example, their type, the participants, and who took the initiative (negotiation, information sharing, problem-solving, disagreement, resistance). This could occur within the broader observational dimensions of space, actor, activity, object, act, event, time, goal, and feeling described by Reeves et al. [28]. Unstructured observation could capture anecdotal and nuanced interactions within meetings that influence the meeting tasks, goals, and outcomes. Interactions would therefore be observed, "in a holistic way that solicits not just their opinions or behaviours, but both of these concurrently" [32, p. 457], to see decision-making and interactions in action, rather than elicit opinions or rhetoric from participants.

3. A critical discourse analysis (CDA) to investigate power differences within the context of establishing interprofessional communication skills and collaboration: how can they work together despite power differences? This methodology is informed by broad understandings of discourse, extending beyond linguistic analysis of the words people say. CDA emerged from social theories, in particular theories of power, which view discourses as the active and constructive components of all social interactions [33]. Within this approach, CDA could also be useful:

- To investigate professional resistance to IPE and IPP;

- To understand how to prepare students for the politics and cultural challenges to effective IPP. This could also entail reflection on ethical challenges, while ensuring the safety of the reflective learning process; and

- To investigate what are the discourses held about our own and each other's disciplines (students, academics, clinicians). 
7

IPE Research

Agenda

Lawn
Journal of Research in Interprofessional Practice and Education
4. A realist evaluation [34] could be used to undertake a comparative investigation of successful and unsuccessful IPE learning situationswhere people actually decide to sit together and learn from each other/where people are brought together within a deliberative process (that may or may not be of their choosing) in order to learn from each other. This could also involve contrasting "staged" learning environments with those that form more naturally because they mean something to people and they construct meaning from it. It might also be useful to investigate an issue faced routinely by many academics when they place students in the practice setting-whether or not these settings are emulating IPP and what the constructs are associated with this practice. Research around such an approach, which pulls together an improved understanding of the various theoretical concepts and constructs to help make the case for emulating IPP based on IPE, would be invaluable in determining what works and what does not.

5. When is the ideal time to teach IPE?

- Should it be early in students' program or not until they have established their own professional identity?

- Does IPE serve different purposes for students at different stages of their professional programs?

- Exploring the impacts of IPE on students' later practice?

- Exploring the role of reflection within the timing of IPE learning activities across the curriculum?

- What was meaningful and what meaning did students construct out of the different learning experiences at different stages of the curriculum? For example, early exposure to IPE might be more about learning basic trust and having openness to others, whereas later immersion in IPE might be more about integrating IPP into the students' construction of their own and other professions.

6. Do academics and clinicians speak a different language in the context of IPE and IPP? Our previous research suggests that academics focus on what students need to know, whereas clinicians focus on the use of the "self" within practice-who I am or need to become [35]. Therefore, research could explore the processes that take students from "what I know" to "who I am." This could help us to understand better the translation of IPE learning into practice. In particular, understanding this potential variation in language may assist students to become more able to integrate holistic and authentic reflective processes into their learning in preparation for practice, and to create a stronger bridge between their student and health professional experience of IPP. 
8

IPE Research

Agenda

Lawn
Journal of Research in Interprofessional Practice and Education

Vol. 6.2

2016
By exploring what is important in that process, we might be better at knowing what to target in the teaching of IPP, and when and how to do it.

7. A longitudinal examination of what it means to do an IPE placement and how those skills translate into further placements and into the workplace. This approach could look at snapshots of the development of meaning over time (the journey). A social constructivist approach would acknowledge that students all start at different points of life or work experience, and bring different constructions to the process of learning and reflection. It could incorporate a retrospective critical-incidents approach to ask students who are in later stages of their learning programs if they remember a clinical placement that was collaborative, what made it collaborative, what made it work, what they learned from that, and what were the IPE opportunities. The few longitudinal studies that have examined the transition and outcomes from IPE to IPP have generally shown mixed results with some showing negative outcomes from IPE interventions, though the reasons for this have been unclear [36-40].

\section{Conclusion}

This article has argued that IPE research is too narrow in its focus. A greater focus on theory is needed to understand the underlying processes involved in IPE, IPP, and the transition between them. This will involve researchers in this field employing more qualitative and mixed-method approaches in addition to the quantitative methods that appear to dominate this field, currently. Researchers should seek theories, models, and methods from such academic disciplines as anthropology, linguistics, economics, implementation science, political science, law, and computer science to inform this research. This is because IPE research that limits itself to investigations in which health professionals are constantly looking at themselves without also looking at the broader social, political, and economic context in which IPP occurs is likely to limit our understanding of how IPE translates to practice. In this article, it is argued that IPE research must involve a greater range of research methods drawn from across social science research methodologies that include anthropology, ethnography, and linguistics, and that are more aligned with understanding organizational practices in their context, such as realist evaluation. This is because student learning and IPP, and the patient-health professional interactions that inform students' and health professionals' reflective practice, are fundamentally socially constructed activities. Indeed, a more theoretical understanding of the processes involved in translating IPE to IPP might also ensure a more authentic investigation of what this all means for personcentred care. Such an investigation could lead to the development of a theorized model that could be tested through a combination of these mixed methods, aligned conceptually with interprofessional patient/family centred collaborative practice. While this is beyond the scope and intention of the current article, it has offered a 
9

IPE Research Agenda

Lawn
Journal of Research in Interprofessional Practice and Education

Vol. 6.2

2016 range of ideas to inform the further development of this model. Therefore, a number of research questions and methodologies have been offered to stimulate further thinking about how to address the gap between IPE and IPP. Reeves [7] concurs with these concerns and argues that we also need to undertake more IPE research that includes the perspectives of patients and learning facilitators, and also more longitudinal work using mixed methods. Thistlethwaite [41] prompts us to view evaluation as being about "causation in a complex system," and argues for the importance of a realist evaluation [34] that involves both outcome and process evaluation so that we can move beyond understanding that something worked or was satisfying to learn, to understanding why and how it made a difference. This would also include an exploration of why the IPE interventions did not appear to be successful for some learners.

This article has briefly discussed a range of theoretical approaches that could be pursued for undertaking more meaningful IPE research. There may be a range of key constructs (such as social constructivism, transformative learning, and complexity) relevant to IPE research that might serve quite different purposes and would therefore require quite different methods of investigation and different underpinning methodology to support that investigation. This article has argued that much of the existing IPE research has not even raised this potential. One example is the need for more theorized research on the concepts associated with the transfer of interprofessional learning from cognitive to action dimensions.

The next challenge is to argue for the importance of this more theoretical and formative research work and to convince funders of its value. This could then mean a future where the vision of undertaking meaningful, longitudinal IPE research that considers the continuum of learning from micro (me and you in our interaction with each other), to meso (us within our organizational or discipline context), to macro (me, you, and us with our community and the broader social, economic, and political environment) might be realized. It might even be one in which a Foucauldian examination of power present in professional cultural barriers or an examination informed by Bourdieu's habitus are possible.

\section{Acknowledgements}

The author would like to thank the members of the faculty IPE working group for their lively discussions, which informed the ideas for this article. The faculty of Medicine, Nursing and Health Sciences at Flinders University supported this research, which occurred within the author's usual academic duties.

\section{References}

1. Centre for the Advancement of Interprofessional Education (CAIPE). (2009). Defining IPE. URL: http://www.caipe.org.uk/about-us/defining-ipe/ [June 11,2016].

2. Curtin University. (2011). Interprofessional capability framework. Perth, AU: Faculty of Health Sciences, Curtin University. URL: https://healthsciences.curtin.edu.au/faculty/ipe_publications.cfm [June 11, 2016].

3. Interprofessional Curriculum Renewal Consortium, Australia. (2013). Curriculum renewal for interprofessional education in health. Sydney, AU: Centre for Research in Learning and Change, University of Technology. URL: http://caipe.org.uk/silo/files/ipecurriculum-renewal-20141.pdf [June 11,2016]. 
10

IPE Research Agenda

Lawn

Journal of Research in Interprofessional Practice and Education

Vol. 6.2

2016
4. Nisbet, G., Lee, A., Kumar, K., Thistlethwaite, J., \& Dunston, R. (2011). Interprofessional health education: A literature review. Sydney, AU: Centre for Research in Learning and Change, University of Technology. URL: http://www.health.wa.gov.au/wactn/docs/IPEAUSlitreview2011.pdf [June 11, 2016].

5. Lapkin, S., Levett-Jones, T., \& Gilligan, C. (2013). A systematic review of the effectiveness of interprofessional education in health professional programs. Nurse Education Today, 33(2), 90-102.

6. Pollard, K.C., Miers, M.E., \& Rickaby, C. (2012). “Oh why didn't I take more notice?” Professionals' views and perceptions of pre-qualifying preparation for interprofessional working in practice. Journal of Interprofessional Care, 25(5), 355-361.

7. Reeves, S., Boet, S., Zierler, B., \& Kitto, S. (2015). Interprofessional education and practice guide No.3: Evaluating interprofessional education. Journal of Interprofessional Care, 29(4), 305-312.

8. Parsell, G., \& Bligh, J. (1999). The development of a questionnaire to assess the readiness of health care students for interprofessional learning (RIPLS). Medical Education, 33(2), 95-100.

9. McFadyen, A.K., Webster, V., Strachan, K., Figgins, E., Brown, H., \& McKechnie, J. (2005). The Readiness for interprofessional learning scale: A possible more stable sub-scale model for the original version of RIPLS. Journal of Interprofessional Care, 19(6), 595-603.

10. Curran, V.R., Sharpe, D., Forristall, J., \& Flynn, K. (2008). Attitudes of health sciences students towards interprofessional teamwork and education. Learning in Health and Social Care, 7(3), 146-156.

11. Mann, M., McFetridge-Durdle, J., Breau, L., Clovis, J., Martin-Misener, R., Matheson, T., Beanlands, H., \& Sarria, M. (2012). Development of a scale to measure health professions students' self-efficacy beliefs in interprofessional learning. Journal of Interprofessional Care, 26(2), 92-99.

12. Sargeant, J., Hill, T., \& Breau, L. (2010). Development and testing of a scale to assess interprofessional education (IPE) facilitation skills. Journal of Continuing Education in the Health Professions, $30(2), 126-131$.

13. Solomon, P., \& Salfi, J. (2011). Evaluation of an interprofessional education community skills initiative. Education for Health, 24(2), 616-625.

14. Kirkpatrick, D.L., \& Kirkpatrick, J.D. (2006). Evaluating training programs: The four levels (3rd edition). San Francisco, CA: Berrett-Koehler Publishers.

15. Barr, H., Koppel, I., Reeves, S., Hummick, M., \& Freeth, D. (2005). Effective interprofessional education: Arguments, assumption and evidence. Oxford, UK: Blackwell.

16. Malt, G. (2015). Cochrane Review Brief: Brief: Interprofessional Education: Effects on professional practice and healthcare outcomes. The Online Journal of Issues in Nursing, 20(2), 12. URL: http://www.nursingworld.org/MainMenuCategories/ANAMarketplace/ANAPeriodicals/OJIN/C olumns/Cochrane-Review-Briefs/Interprofessional-Education.html [October 20, 2016].

17. Reeves, S., Perrier, L., Goldman, J., Freeth, D., \& Zwarenstein, M. (2013). Interprofessional education: Effects on professional practice and healthcare outcomes (update). Cochrane Database of Systematic Reviews Issue 3. Art. No. CD002213. URL: http://onlinelibrary.wiley.com/doi/10.1002/14651858 .CD002213.pub3/full [October 20, 2016].

18. Olson, R., \& Bialocerkowski, A. (2014). Interprofessional education in allied health: A systematic review. Medical Education, 48(3), 236-246.

19. Jorm, C.M., Nisbet, G., Roberts, C., \& Gordon, C.J. (2016). Using complexity theory to develop a student-directed interprofessional learning activity for 1220 healthcare students. BioMed Central Medical Education, 16, 199-213.

20. Guitard, P., Dubouloz, C., Savard, J., Metthe, L., \& Brasset-Latulippe, A. (2010). Assessing interprofessional learning during a student placement in an interprofessional. Rehabilitation University Clinic. Journal of Research in Interprofessional practice and education, 1(3), 231-246.

21. Gredler, M.E. (1997). Learning and instruction: Theory into practice (3rd edition). Upper Saddle River, NJ: Prentice-Hall.

22. Hommes, J. (2014). How relations, time and size matter in medical education. [PhD thesis]. Maastricht, NL: Maastricht University. URL: http://digitalarchive.maastrichtuniversity.nl /fedora.guid:96a95df-07c3-46c7-8fcf-05110423e9f9/ASSET1 [June 11, 2016].

23. Mezirow J. (2003). Transformative learning as discourse. Journal of Transformative Education, 1(1), 58-63.

24. Blanchet, K., \& James, P. (2012). How to do (or not to do) ... a social network analysis in health systems research. Health Policy and Planning, 27(5), 438-446.

25. Borgatti, S.P., Everett, M.G., \& Johnson, S.C. (2013). Analyzing social networks. London, UK: Sage.

26. Barr, H. (2013). Towards a theoretical framework for interprofessional education. Journal of Interprofessional Care, 27(1), 4-9.

27. Suter, E., Goldman, J., Martimianakis, T., Chatalalsingh, C., DeMatteo, D.J., \& Reeves, S. (2015). The use of systems and organizational theories in the interprofessional field: Findings from a scoping review. Journal of Interprofessional Care, 27(1), 57-64. 
11

IPE Research

Agenda

Lawn
28. Reeves, S., Kuper, A., \& Hodges, B.D. (2008). Qualitative research methodologies: ethnography. British Medical Journal, 337, 512-514.

29. Arber, A. (2008). Team meetings in specialist palliative care: asking questions as a strategy within interprofessional interactions. Qualitative Health Research, 18(10), 1323-1335.

30. Arman, R., Dellve, L., Wkstrom, E., \& Tornstrom, L. (2009). What health care managers do: Applying Mintzberg's structured observation method. Journal of Nursing Management, 17(6), 718-729.

31. Hendry, J., \& Seidl, D. (2003). The structure and significance of strategic episodes: social systems theory and the routine practices of strategic change. Journal of Management Studies, 40(1), 175-196.

32. McDonald, S. (2005). Studying actions in context: A qualitative shadowing method for organizational research. Qualitative Research, 5(4), 455-473.

33. Fairclough, N. (2003). Analysing discourse: Textual analysis for social research. London, UK: Routledge.

34. Pawson, R., \& Tilley, N. (1997). Realistic evaluation. London, UK: Sage.

35. Ward, H., Gum, L., Attrill, S., Bramwell, D., Lindeman, I., Lawn, S., \& Sweet, L. (in review). Educating for interprofessional practice: Moving from knowing to being, is it the final piece of the puzzle? BioMed Central Medical Education.

36. Coster, S., Norman, I., Murrells, T., Kitchen, S., Meerabeau, E., Sooboodoo, E., \& d'Avray, L. (2008). Interprofessional attitudes amongst undergraduate students in the health professions: A longitudinal questionnaire survey. International Journal of Nursing Studies, 45(11), 1667-1681.

37. Curran, V.R., Sharpe, D., Flynn, K., Button, P. (2010). A longitudinal study of the effect of an interprofessional education curriculum on student satisfaction and attitudes towards interprofessional teamwork and education. Journal of Interprofessional Care, 24(1), 41-52.

38. Kururi, N., Makino, T., Kazama, H., Tokita, Y., Matsui, H., Lee, B., Kanaizumi, S., Abe, Y., Achida. Y., Asakawa, Y., Shinozaki, H., Tozato. F., \& Watanabe, H. (2014). Repeated cross sectional study of the longitudinal changes in attitudes toward interprofessional health care teams amongst undergraduate students. Journal of Interprofessional Care, 28(4), 285-291.

39. McFadyen, A., Webster, V., Maclaren, W., \& O’Neill, M. (2010). Interprofessional attitudes and perceptions: Results from a longitudinal controlled trial of pre-registration health and social care students in Scotland. Journal of Interprofessional Care, 24(5), 549-564.

40. Pollard, K., \& Miers, M. (2008). From students to professionals. Results of a longitudinal study of attitudes to pre-qualifying collaborative learning and working in health and social care in the United Kingdom. Journal of Interprofessional Care, 22(4), 399-416.

41. Thistlethwaite, J.E. (2015, October 6). Work-based assessment of interprofessional teamwork: Competencies, tools, observation and feedback. Paper presented at the Inaugural Interprofessional Health Education and Practice Conference, Melbourne, Australia.
Journal of Research in Interprofessional Practice and Education

Vol. 6.2

2016 